\title{
CrimRxiv
}

\section{The Good Cause: Theoretical Perspectives on Corruption}

Gjalt De Graaf, Patrick Von Maravić, Pieter Waagenar

Published on: Mar 04, 2022

License: Creative Commons Attribution 4.0 International License (CC-BY 4.0). 
